\title{
Research and analysis of the results from the tribotester test for piston
}

Piston - ring - cylinder assembly of combustion engine has a lot of friction pairs examples, also one of them which decide about fastness to wear, it means first sealing ring - cylinder, called further very simply ring - cylinder unit. During work of this unit we can observe wear of piston, precisely - of coating which is deposited on ring to prolong service life. Objective of this work was to realize a test of roll-block type on tribotester to set durability of piston sample. Within the framework of this test were investigated a prototyped piston's rings with diamond embankment. Piston rings are made of diamond coating technology with a porous chromium coating, where in pores is deposited on said diamond powder with a grain size about 1 micron. The work will be carried out of an analysis of collaboration piston - rings - cylinder unit in internal combustion engine and an analysis of the use of hard materials in friction pairs, including powders. The work aims to show the possibilities and benefits of the application of new protective coatings to reduce their wearing, which is consistent with the observed trend of technology development.

Key words: piston, diamond, coating, tribotester, friction

\section{Introduction}

This article presents one of the stages in the research of the newly developed vacuum seal consisting of a sealing piston ring and a cylinder designed for an internal combustion engine, in which the novelty is an innovative diamondderivative coating with very good anti-wear properties.

The purpose of the coating is not only to protect the item against wear, but also to improve its integrity. Diamond-coated coating is classified as hard coatings. Diamond copolymer coatings are amorphous raw materials with very thin layers and their properties depend on the conditions and the type of technology used in the production. For the first time, they were made by Aisenberg and Chabot in 1969 to produce an amorphous layer without hydrogen, thanks to the argon in which carbon beam beams were previously cooled. This has led to the ever-increasing use of this material as a tough, anti-wear coating with high resistivity. These coatings are named in various ways. The most common name is DLC. The name, precisely the structure of the DLC coating is derived from the high number of sp3 bonds present in the amorphous carbon, which at the same time affects the properties of the coating. This coating is characterized by high hardness, stability and smooth surface. Coatings can undergo some modifications by using such metal elements as vanadium, chrome, titanium or molybdenum, thereby obtaining suitable structures that interfere with parameters such as coefficient of friction, stress, adhesion and wear. In our case, the coating contains addition of chromium.

In general, the characteristics of diamond-shaped coatings are:

- higher hardness than traditional materials, within 10-60 GPa,

- high adhesion to the substrate,

- High mechanical, physical and chemical stability,

- coefficient of friction below 0.1,

- high electrical resistance up to $1016 \Omega$,

- high abrasion resistance up to $10^{-7} \mathrm{~mm}^{3} / \mathrm{Nm}^{-1}$,

- as well as optical transparency.

Comparative research on tribotester test at model stations is considered as exploratory because many simplifica- tions are used. The purpose of these studies is to compare the results of the tribological processes (wearing) that occur in the material connections in friction pairs.

The research was done on a roll-block type tribotester. The test elements are a rotating countersample in the form of a roll and a fixed sample in the form of a block. Key loads in this type of friction pair test are unit pressure $[\mathrm{MPa}]$ and linear speed $[\mathrm{m} / \mathrm{s}]$. High pressure and low speed produce extremely difficult conditions in the engine.

\section{Test on tribotester}

\subsection{Preparation}

The test was performed on a tribotester marked with the T05 symbol in Radom, which is suitable for tests of lowfriction coatings. The sample is in the form of an annular roller, while the sample is characterized by a concave test surface, thereby adhering to the roll and simultaneously forming a contact of $100 \mathrm{~mm}^{2}$. The working surfaces of the samples are covered with a diamond-like coating deposited by physical gas phase deposition in various ratios with chromium addition.
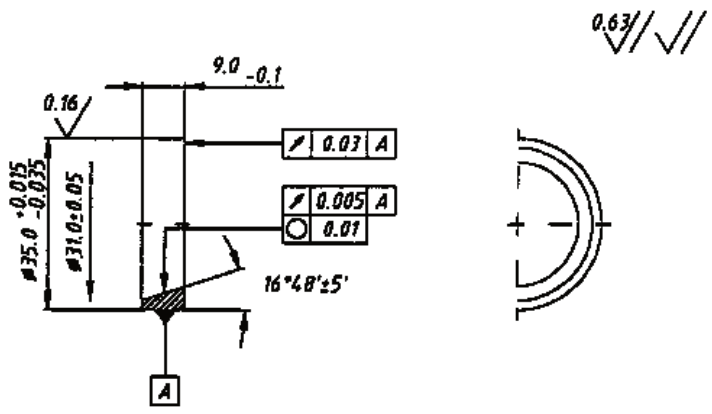

Fig. 1. Sample intended to tribotester test

A linear velocity of $1.25 \mathrm{~m} / \mathrm{s}$ and a unit pressure of 5 MPa have been used for the tests, resulting in very severe operating conditions (very much in excess of normal operating conditions) which are very similar to those that occur at the beginning of the expansion stroke of 4 - with internal combustion engine in the vicinity of the $\mathrm{ZZ}$ of the first 
sealing piston ring. The phenomenon of mixed friction appeared here, as evidenced by the excess of 0.01 typical of liquid friction. The friction was done in a synthetic oil environment named GOLD SINTHESIS VENOL 5W-40. In test we considered 6 samples, but after the research we typed sample T-2 as the best composition of \% diamond and $\%$ of chromium.

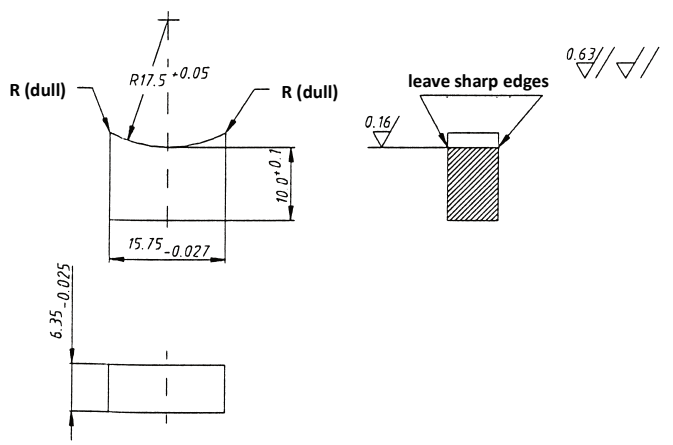

Fig. 2. Countersample intended to tribotester test

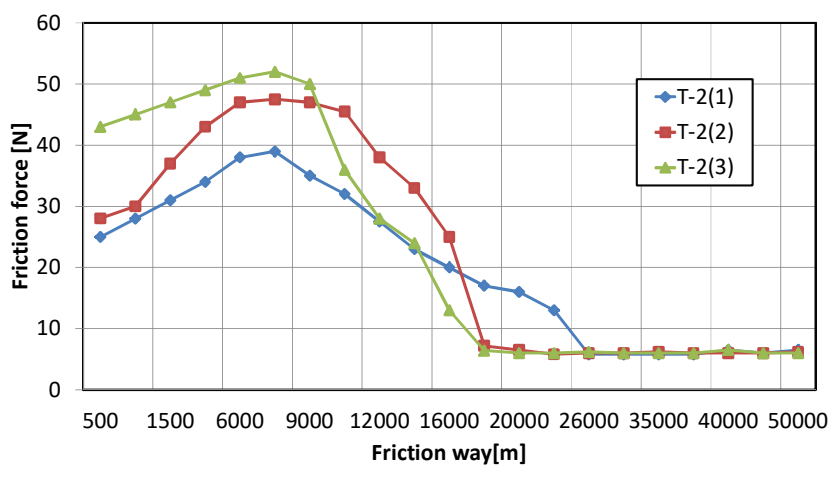

Fig. 3. Course of variation of friction force from road for samples marked T-2

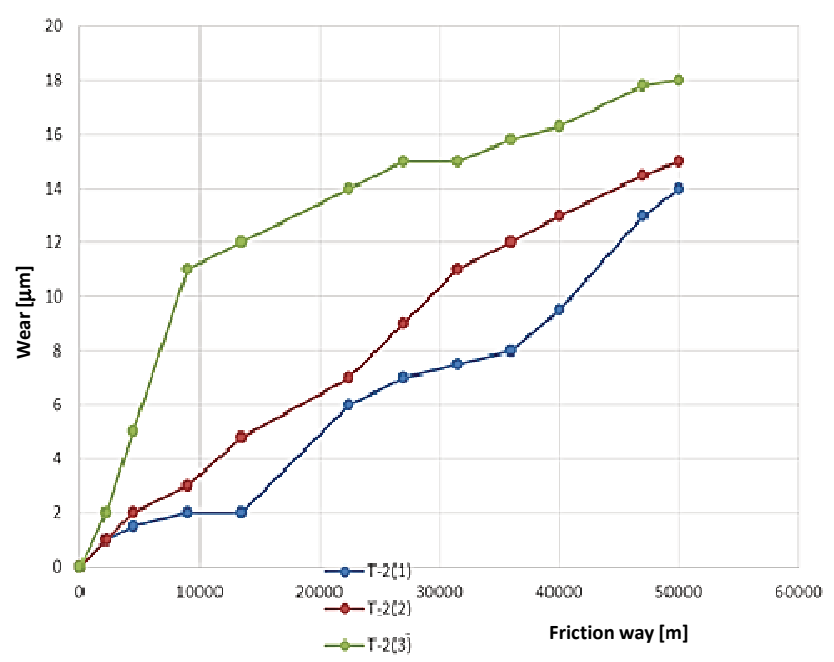

Fig. 4. Sum of wearing graph for T-2 friction node

The friction force measurements at the testing node were recorded at a certain time interval, and on this basis was compiled a source graph for 50,000 meters long of run in 3 trials (Fig. 3).

The aggregate wear of rings and blocks was performed directly on the T-05 tester during breaks and at a steady- state temperature of $25^{\circ} \mathrm{C}$. Measurement was done without disassembly of the friction node and at a load of $5 \mathrm{MPa}$. For measurements, a clock sensor is used in the value of the parcel $\mathrm{We}=0.002 \mathrm{~mm}$, in the same angular position to eliminate the ring error. It should be noted here that the aggregate wear of the friction node is also burdened by the wear of bearings in the spindle and the angular position of the spheres. The results shows the Fig. 4.

\subsection{Results}

Of course, these studies do not fully reflect the working conditions of the steamed piston ring cylinder. First of all, there is no burning process. The material from which the piston ring model was made, was made of steel from which the piston rings were made and chrome-plated. Were designed and made 6 variants of the coating. The block was made of gray cast iron - typical metarial of the cylinder. Thus, the cooperation of the materials in the model of the same steamed pair, which are used in the tested for combustion engines, has been ensured. The selected motion parameters during the tribotester test result in extremely difficult operating conditions, ie a load close to the maximum working cycle of the actual steam seal ring cylinder, at the same time a rotational speed of only about $30 \%$ of idle speed for individual motors. The trial was conducted in the gears (according to test procedure on tribotester type T05), each of which has a friction path of 1250 meters. For each test sample count is 40 gears, which means a friction path of 50 000 meters. Experience shows that friction coefficient stabilizes after this friction path. The tests are conducted in the presence of Synthese Venol 5W40 synthetic elf lubricant. As a result of the research work we have obtained the variation of the frictional forces as a function of the friction path, from which it is possible to calculate friction coefficient values and friction coefficient sum values. Fig. 3 illustrates, for example, the course of friction force as a function of the friction path for a sample of T-2, the composition of which is the most favorable from the viewpoint of co-operation with the counterpart (carbon percentage in the chromium coating was about $1 \%$ ).

Analyzes of the measurement results allowed to determine the final form of the diamond embankment. First of all, the percentage of diamond crystals in the shell was decided. Based on the above research was decided to have a content of about 0.75 mass $\%$, which means $1.47 \%$ by volume diamond fill in the shell.

Within this task, material, shape and other rings and cooperating cylinders were also carried. It had examined piston rings with a diamond filler of 0.5 to $4.5 \mu \mathrm{m}$ in diameter and a blend of corundum.

The final composition of the coating is the result of optimization work and its sample composition is shown in the table below.

Tab. 1. Sample composition of PCD coating

\begin{tabular}{|l|c|c|c|}
\hline Elem \% & C & Al & Cr \\
\hline Min: & 0.640 & 0.000 & 98.020 \\
\hline Max: & 0.900 & 0.090 & 98.570 \\
\hline Mean: & 0.770 & 0.047 & 98.306 \\
\hline StdDev: & 0.096 & 0.030 & 0.195 \\
\hline \% MAS & 0.75 & 0.09 & 99.20 \\
\hline \% V & 1.49 & 0.14 & 98.36 \\
\hline
\end{tabular}




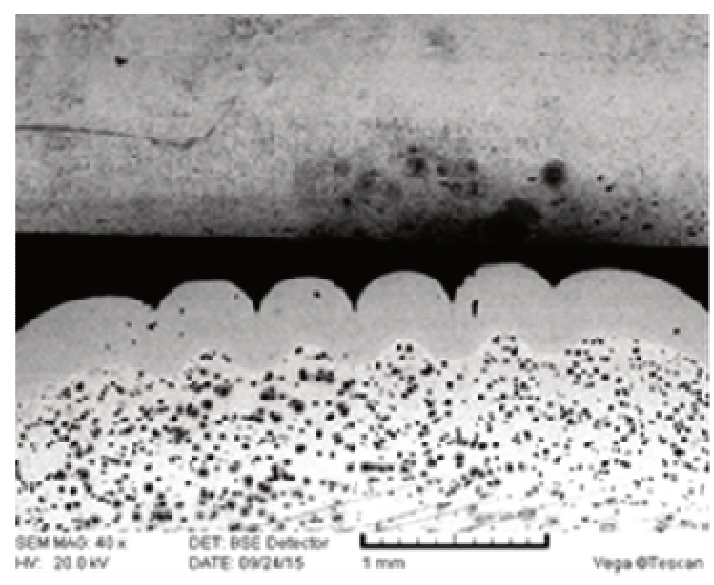

Fig. 5. A cross sectional view of the top layer of an engine ring with a PCD coating

Linear wear of rings and blocks was also measured on the Carl Zaiss Jena vertical optimizer, ring and block measurements were made before and after friction tests. The dimension difference should be treated as linear consumption. Measurement uncertainty is $0.001 \mathrm{~mm}$. Results obtained in this way are presented in the form of bar charts in the table below, where we can observe that the smallest difference of linear wear in case of sample T- 2 .

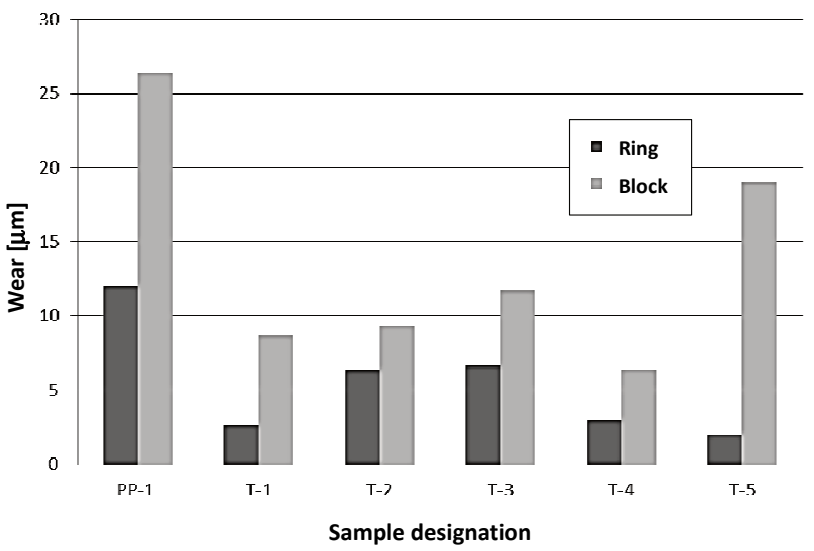

Fig. 6. Linear wear of rings and blocks after friction test

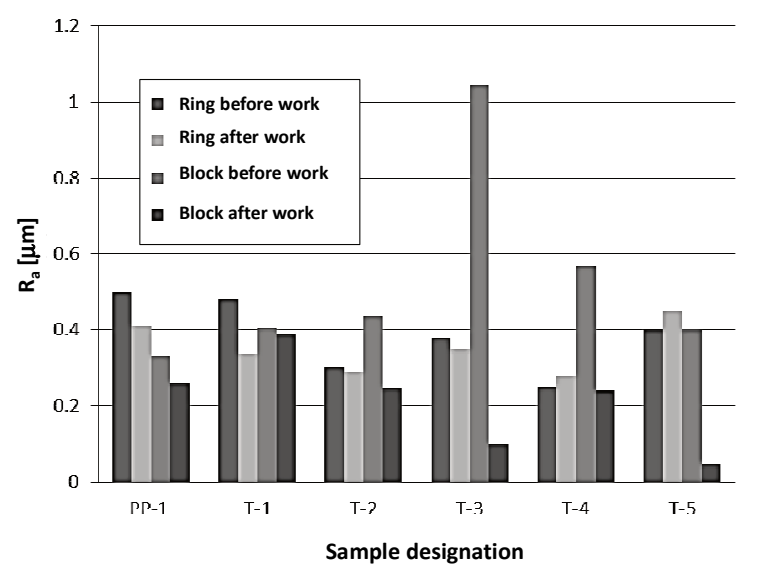

Fig. 7. Bar chart of the change of the roughness parameter

Roughness measurements of samples and counters were also carried out before and after the friction test on a com- puterized profilograph L50 topography produced by Advanced Manufacturing Technology in Cracow. The results of Ra parameter changes are presented in the form of bar graphs below, where we can see that the smallest change in roughness parameter between before and after the test appear in case of sample T-2:

Due to the relatively low linear wear of accelerated comparative tests, the friction path has been extended to 50,000 meters. In the oil exchanged after each series of tests, was observed a black precipitate.

In addition, micro hardness was measured by Vicers methodolody and performed at load of $100 \mathrm{G}$. The results of the measurements are shown in the bar graph in Fig. 8.

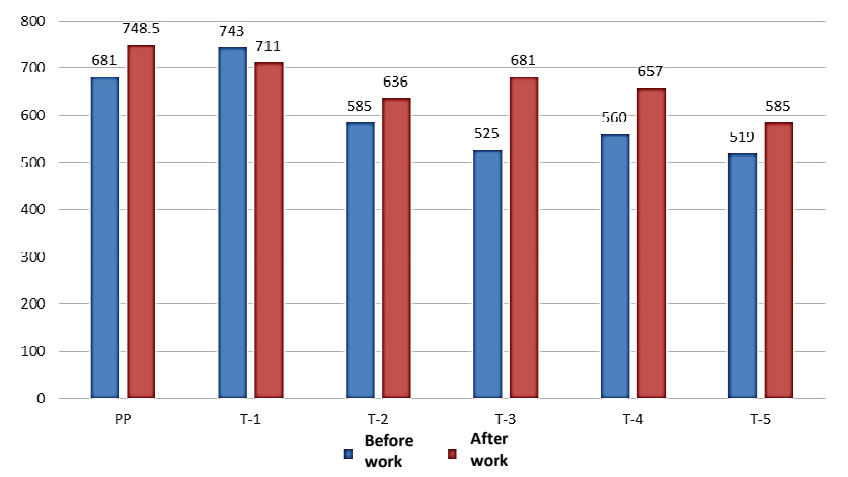

Fig. 8. Bar chart of the hardness of the rings before and after the friction test

The best sample turned out to be T-2, but to compare we can see f.ex. the results of the next sample with the less quantity of diamond powder in coating, where we can observe that the course of variation of friction force from the road for samples marked T-3 is very uneven:

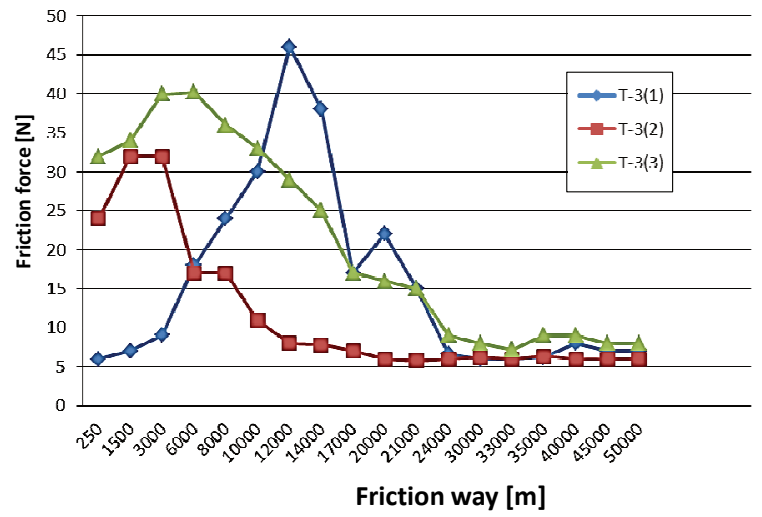

Fig. 9. Course of variation of friction force from road for samples marked T-2

\section{Conclusion}

Diamond - derivative coatings are mainly characterized by a lower friction coefficient and a much greater resistance to wear in comparison to rings that are covered by the common superhard coatings. Without a doubt, the application of such coatings will have an impact not only to extend the life of system piston - ring - cylinder, but also will reduce fuel consumption even under the most strenuous conditions of work of the unit. 
Solutions to the given research problem is based on the results of these studies of tribotester test for piston. They allow to acquire new knowledge and skills in the manufacture of coatings PDC, in particular the constitution layers of diamond coating with a specific weight percentage composition. Positive test results realized in tribotester pose a real chance to increase the quantities of produced rings with diamond coating for f.e. large combustion engines powering locomotives or small inland waterway vessels (very positive results in the endurance tests) and in the future perhaps for small internal combustion engines for use in vehicles like a cars, thus extending their life.

Studies show that with \% increasing of the carbon in the coating composition and decreasing of the hydrogen amount is related to improved strength and wear resistance at the time of no lubricating function of the lubricant. The use of diamond - derivative coatings is a new direction in the development of technology for internal combustion engines. Replacement of worn parts of the piston - ring cylinder set would decrease considerably their properties and their improvement has a definite dimension, so the use of such modern shells prolonging the life could change a lot on what evidence may be carried out research and very promising results. These the hardest coatings available on the market today are increasingly used, mainly in the automotive and electronic equipment. The properties of these coatings and getting their increased popularity also contribute to the decrease in costs associated with their production, and the problem of their insufficient thickness will likely be solved with the most modern methods of hardfacing on components.

Diamond - derivative coatings can be applied to elements working in high-speed diesel engines and because of the opportunity to work at very high temperatures. They also exhibit good adhesion to the substrate steel and cast iron, and less stress their own, so they seem to be a breakthrough in the use of materials with excellent tribological properties. A complete set of advantages of applying diamond - derivative coatings contains very high hardness (70 $\mathrm{GPa}$ ), high value electrical resistance, relatively low weight, and most importantly, low coefficient of friction and excellent wear resistance.

The diamond-based coating, exemplified by the DLC coating, is an example of a very hard surface coating that protects the element from wear. This layer of the coating affects tribological cooperation in the friction node and interaction with the environment. In turn, the core of such a coating is designed to provide adequate hardness, durability or thermal conductivity.

In a modern approach to coatings, coatings are used, which in the base composition contains carbon capable of crystallizing into graphite or diamond. A number of studies are being conducted based on the use of a diamond-based hard coating and successive research is being increasingly analyzed. Undoubtedly, the knot elements that are covered with diamond-coated coatings and cooperate with each other frictionally have less resistance. This, in turn, has a moderate linear wear on the parts and, what is important - a low friction coefficient, thus improving the mechanical properties of the system and therefore being used in all industries where there is a high risk of wear and high friction. There are several barriers to the widespread use of diamond-based coatings in the automotive sector. These coatings are small in thickness and this lowers its durability and it is difficult to obtain a smooth finish that improves tribological properties. Therefore, the DLC layer works with a layer of another origin and is applied eg in the presence of a chromium coating.

An important feature is that abrasive wear resistance increases with increasing hardness, which has a similar value on both working surfaces. This was the beginning of the discussion on diamond-based coatings, which is considered to be the hardest material.

\section{Bibliography}

[1] BUCKMASTER, J., CLAVIN, P., LINAN, A. et al. Combustion theory and modeling. Proceedings of the Combustion Institute, Vol. 30, pp. 1-19, Pittsburgh 2005.

[2] BURAKOWSKI, T., Wierzchoń, T. Inżynieria powierzchni metali, Wydawnictwo Naukowo-Techniczne. Warszawa 2004.
[3] ISKRA, A. Symulacja parametrów pracy pierścienia na stanowisku modelowym. Materiaty konferencyjne Konmot '94 Silniki Spalinowe - konstrukcja i badania, Kraków Raba Niżna 1994, 93-104.

[4] MADEJ, M. Właściwości systemów tribologicznych z powłokami diamentopochopdnymi. Wydawnictwo Politechniki Świętokrzyskiej. Kielce 2013.
Borkowska Joanna - Faculty of Mechanical Engineering at Wrocław University of Technology.

e-mail: Joanna.Borkowska@pwr.edu.pl
Kaźmierczak Andrzej, DSc., DEng. - Faculty of Mechanical Engineering at Wrocław University of Technology.

e-mail: Andrzej.Kazmierczak@pwr.edu.pl 